\title{
Structural Firefighting Suits: Futuristic Materials and Designs for Enhanced Comfort
}

\author{
Prasun Kumar Roy*, Praveen Rajput and Mahipal Meena
}

Centre for Fire, Explosive and Environment Safety, India

ISSN: 2576-8840

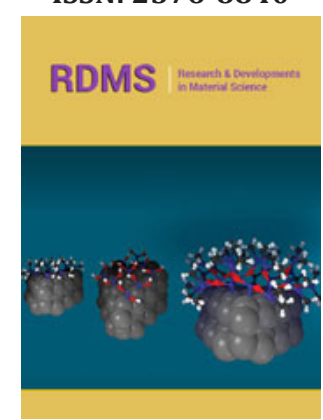

*Corresponding author: Prasun Kumar Roy, Centre for Fire, Explosive and Environment Safety, DRDO, Timarpur Delhi 110054, India

Submission: 眥 November 09, 2020

Published: 制 November 24, 2020

Volume 14 - Issue 4

How to cite this article: Prasun Kumar Roy*, Praveen Rajput and Mahipal Meena . Structural Firefighting Suits: Futuristic Materials and Designs for Enhanced Comfort. Res Dev Material Sci. 14(4). RDMS.000841. 2020. DOI: 10.31031/RDMS.2020.14.000841

Copyright@ Prasun Kumar Roy. This article is distributed under the terms of the Creative Commons Attribution 4.0 International License, which permits unrestricted use and redistribution provided that the original author and source are credited.

\section{Abstract}

The present work aims to briefly overview the protective clothings being used by the firefighters during structural firefighting operations. Future directions towards improving the physiological comfort level offered by the ensemble without compromising on the level of protection against heat loads are also discussed.

\section{Introduction}

Structural firefighting suits belong to the sub-class of protective functional clothings, which are designed with a view to protect our first responders who fight fire during emergency operations. In these scenarios, there is a possibility of the firefighter being exposed to additional hazards like liquid spills and sparks as well [1]. Therefore, a properly designed functional firefighting clothing is required which provides requisite level of protection not only against thermal loads but hazardous liquids, physical and electrical hazards as well. In addition, it should be durable, washable, most importantly, be comfortable for the wearer.

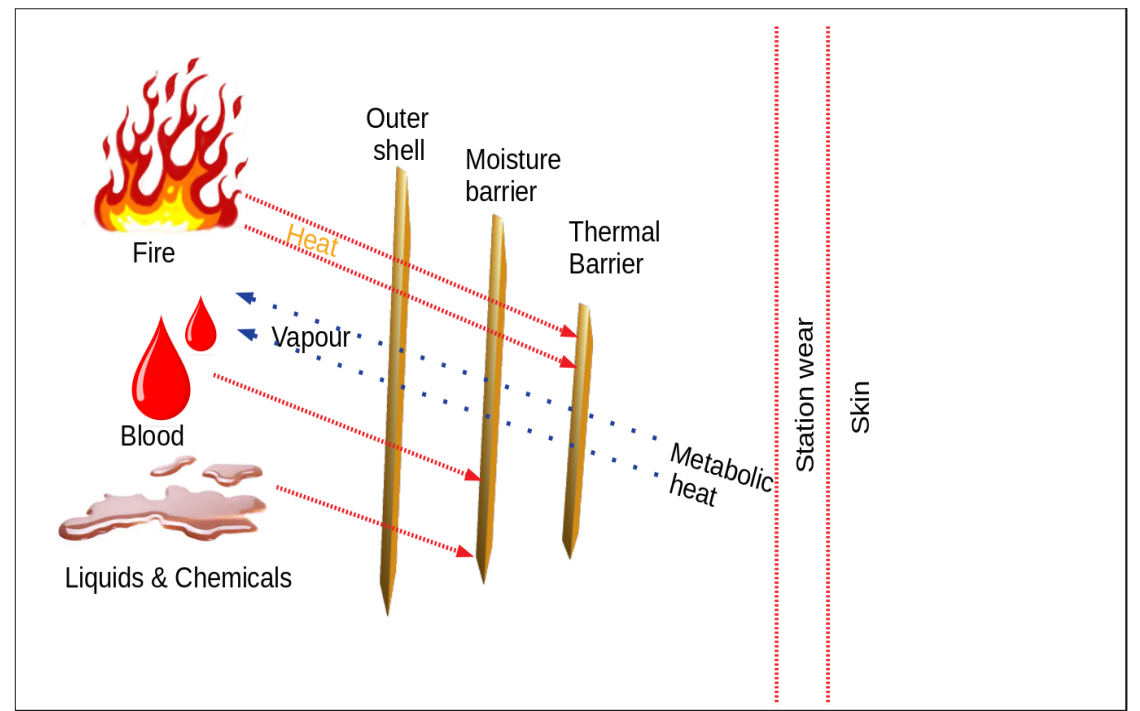

Figure 1: A schematic representation of the multilayer ensemble of structural firefighting suit.

The entire firefighters' protective equipment includes a turnout coat, pants, boots, hood, gloves, self-contained breathing apparatus and a helmet, as governed by the National Fire Protection Association) 1971 and 1981 standards. The firefighting suits (as per NFPA 1971/ EN 469 or НПБ 162-02 or IS 16890) are all multilayer ensembles [2], a representative assembly being shown in Figure 1. The outer layer of the ensemble resists ignition when subjected to thermal radiation or short periods of direct flame contact. It also imparts protection against abrasion, cuts, lacerations. Beneath it, exists a moisture barrier layer, which plays a critical role in the suit. Firstly, it prevents the entry of water to the underlying thermal layer, which if enters will displace the air in the thermal barrier, thereby decreasing the level of thermal insulation, subsequently leading to scald injuries. Secondly, the moisture barrier is required to permit the outward movement of perspiration, leading to reduced metabolic heat buildup. 
Therefore, the moisture barrier should offer a minimum level of breathability along with confering penetration resistance against body fluids and chemicals like battery acids, gasoline, hydraulic fluid etc which keeps the fire-fighter dry and protected. Next in the sequence is the thermal barrier layer, the role of which is to impart the requisite level of thermal insulation to the wearer. This layer is usually made up of a non-woven fabric which traps air pockets for enhanced insulation.

It is to be noted that the expectations from a fire fighter suit are rather contradictory. On one hand, the firefighter needs to be protected from thermal loads, however increasing the thermal insulation results in physiological discomfort. Being homoemothermic, humans need to maintain a stable internal body temperature regardless of the external environment, the inability of which leads to heat strain [3]. Notably, burn injuries experienced by firefighters may reduce due to increased number of layers, but can lead to increase in incidents related to fatigue, exhaustion, heat strain and fatalities [4].

The efficiency of a firefighter clothing is evaluated primarily on the basis of two criteria: firstly, the restriction on the amount of heat load reaching the wearer and secondly, the ease of removal of the metabolic heat produced by the firefighter himself during the strenuous physical activities. In NFPA 1971, these requirements are quantified in terms of the Total Heat Loss (THL) and Thermal Protective Performance (TPP) and an ideal suit would be one which exhibits an optimal balance of these two [5]. The former parameter, i.e. THL is a measure of breathability, and is evaluated at the fabric level (garment composite), and the latter, i.e. TPP is an indication of the materials ability to protect against thermal loads, both being inversely proportional. As per NFPA 1971, a minimum TPP rating of 35 and a THL of $205 \mathrm{~W} / \mathrm{m}^{2}$ is mandatory for a structural firefighting suit. In the other standards EN 469 and IS 16890, these are measured in terms of heat transfer (flame exposure and radiant exposure) and water vapour resistance.

It is to be noted that the tests mentioned above are a function of the fabric materials in the three-layer system only, and do not consider additional padding, trim, labels, pockets and other reinforcements. In practice, however these suits are worn on the 3-D human form which create additional air gaps between the layers, which further vary at different locations; an issue which is not catered for in the present standards. Also, there is a requirement of a manikin THL benchmark for reducing heat strains, as currently, only fabric level heat loss values are used in NFPA standards. In the near future, there are primarily two broad domains, where developments in firefighter suit designs can be expected: namely material development and design improvisations.

\section{Innovative materials for futuristic firefighter suits}

The present-day material choices for thermal protective clothing include fabrics which are formed from fibers which are flame resistant in view of their inherent structure [6]. Polybenzimidazoles, polybenzoxazoles and melamine formaldehyde based fibers possess heterocyclic moeities in the main chain, modacrylic fibers contain vinyl/vinylidene chloride groups, polyimides possess a rigid (ladder type) structure and the double bond character of the $\mathrm{C}-\mathrm{N}$ bond available in the $\mathrm{m}$ - and p-aramids conjugate between the amide groups and the aromatic rings resulting in increased chain rigidity and liquid crystalline nature [7]. Polyphenylene sulfide fibers consist of aromatic rings linked together by sulfide functionality. All the above-mentioned features help the fibers retain their physical properties at elevated temperatures. It is to be noted that all the commercially available fabrics are prepared from blends of different fibers, each having its own desirable property.

The characteristic property for screening polymers for firefighting application is its susceptibility to combustion, which is quantified in terms of the Limiting Oxygen Index (LOI): the minimum oxygen concentration required for its sustained burning. For all practical purposes, all the flame resistant fibers have an LOI of $>27$. However, LOI gives only a partial evidence of the materials behaviour towards heat or flames, and there are several other thermal factors which are important in the context of clothing, particularly thermal conductivity and heat capacity.

Future developments in this area would primarily aim at using lighter materials to reduce the overall weight of the fire suit, which will reflect on increased physiological comfort. Recent studies have revealed that introducing nanomaterials can reduce the flammability of polymers by reducing the heat release rate, increased flame-out and auto-extinguishment properties. The underlying mechanisms is the alteration in the degradation pathway, i.e. formation of nanoparticle reinforced charred protective layers on the surface [8].

The latest developments in this area are in the field of aerogels and phase change materials. The former represents a class of material which are extremely light and offer excellent thermal insulation as well, while the phase change materials can absorb heat energy [9]. Lately, the potential of intumescent coatings on improving the fire retardancy of textiles have also been explored [10]. The use of shape memory alloys and thermoresponsive polymers [11] which can maintain or create insulating layers or air gaps within garment systems are also being researched [12]. In view of the extremely low density of the hollow glass micro balloons, along with their low thermal conductivity, the potential of syntactic films can also be explored [13]. However, these ideas are presently in the experimental stages primarily because of the slow response of these materials, economic factors, limited durability.

Reducing the fiber dimensions can also alter the performance of fibers under fire scenario. Lately, nanofibrous flame resistant coatings formed by electrospinning process have been reported [14]. It is to be noted that these porous fibers have enormous potential as a breathable moisture barrier layer [15]. The presence of pores can facilitate free movement of the water vapour formed during perspiration, leading to increased level of comfort $[16,17]$. 
However, it is to be noted that irrespective of the improvement in breathability, any compromise on the protection level (as indicated by TPP) is unacceptable. This is primarily the reason why many novel materials that have found wide acceptance in normal outerwear have not yet been accepted in firefighting clothing (e.g. moisture wicking, high stretch, and ultra-lightweight fabrics). In this context, the use of modelling techniques for screening potential materials for suit applications should be explored [18].

\section{Design modifications}

The most obvious strategy towards improving the comfort level of a firefighter is the introduction of passive or active ventillation. Passive vents are the ones which will always be in place, while active vents are those which remain open under normal conditions but have to be closed during the fire scenario. Other possibilities include alteration in the assembly of the layers, reduction in the air gap volume and system modularity. Recently, as a part of the "Revolutionary Modern Turnout suit" project, sponsored by the United States Department of Homeland Security, all these aforementioned design modifications have been explored [19]. A significant improvement in heat loss was observed when ventilation openings and modularity were introduced to the clothing system [20]. In view of these studies, the next generation firefighter suits are expected to have ventillation at appropriate locations to help relieve heat stress. Studies have also revealed that the addition of just a single layer of an outer shell fabric leads to significant increase in TPP (from 38 to 53), associated with a concomitant decrease in THL as well $\left(205 \mathrm{~W} / \mathrm{m}^{2}\right.$ from $\left.263 \mathrm{~W} / \mathrm{m}^{2}\right)$. For all practical purposes, firefighter suits are not only fitted with pockets, they are also fitted with additional reinforcements in the knee and shoulder areas as well as reflective layers, all of which affect the physiological response of the firefighter adversely; an issue which needs to be addressed. Another point of concern is the availability of the present generation firefighter suits for a single sex workforce [21]. With the increase in the number of female firefighters, the futuristic suits should be ergonomically designed keeping in view the difference in the build and the anthropometric data for the targeted workforce.

It is to be noted that in addition to the basic fiber material, there are a plethora of other factors which affect the behaviour of the fabrics under a fire scenario, particularly the weave pattern, fabric direction and the torsion of the constituent yarns [22]. Closed fabric constructions, functional blended fibers, changes in the direction, weight and torsion of the constituent yarns can also lead to improved flame resistance.

Recent developments in the field of nanotechnology permit the integration of flexible textile sensors with the protective clothing to form smart textiles [22,23]. These can be used to record vital physiological data of the firefighters such as respiratory \& cardiac activity, blood pressure, body temperature and transmit the same to the base station, which can help in taking informed decisions. The lightweight firefighter gear of the future will have integrated vital-sign sensors as well indoor tracking, which will definitely reduce the number of injuries and fatalities of our fire responders.

\section{Acknowledgment}

The authors would like to thank DRDO for funding this work through ST/16-17/CFE-1327.

\section{References}

1. Guowen S, Faming W (2018) Firefighters' clothing and equipment. Taylor \& Francis.

2. Jacek R, Karolina S, Daria K, Maciej B (2016) Comparison of requirements and directions of development of methods for testing protective clothing for firefighting. Fibers Text East Eur 24(119): 132-136.

3. Mcquerry M, Barker R, Denhartog E (2018) Relationship between novel design modifications and heat stress relief in structural fi re fighters' protective clothing. Appl Ergon 70: 260-268.

4. Su Y, Yang J, Song G, Li R, Xiang C, et al. (2018) Development of a numerical model to predict physiological strain of firefighter in fire hazard. Sci Rep 8(1): 3628.

5. Kim JH, Kim DH, Lee JY, Coca A (2017) Relationship between total heat loss and thermal protective performance of firefighter protective clothing and consequent influence on burn injury prediction via flame-engulfment manikin test. Proc Hum Factors Ergon Soc Annu Meet 61(1): 1468-1471.

6. Bajaj P (1992) Flame retardant materials. Bull Mater Sci 15(1): 67-76, 1992.

7. Jassal M, Ghosh S (2002) Aramid fibres - an overview. Indian J Fibre Text Res 27(3): 290-306.

8. Nayak R, Houshyar S, Padhye R (2014) Recent trends and future scope in the protection and comfort of fire-fighters' personal protective clothing. Fire Sci Rev 3(1): 1-19.

9. Shaid A, Wang L, Padhye R (2015) The thermal protection and comfort properties of aerogel and PCM-coated fabric for firefighter garment. J Ind Text 45(4): 611-625.

10. Fang F (2015) Intumescent flame-retardant coatings on cotton fabric of chitosan and ammonium polyphosphate via layer-by-layer assembly. Surf Coatings Technol 262: 9-14.

11. Mukhopadhyay A, Vinay Kumar M (2008) A review on designing the waterproof breathable fabrics part I: Fundamental principles and designing aspects of breathable fabrics. Journal of Industrial Textiles.

12. Bartkowiak G, Dabrowska A, Greszta A (2020) Development of smart textile materials with shape memory alloys for application in protective clothing. Materials (Basel) 13(3): 1-17.

13. Ullas AV, Kumar D, Roy PK (2019) Epoxy-glass microballoon syntactic foams: Rheological optimization of the processing window. Adv Polym Technol 2019.

14. Gallo E, Fan Z, Schartel B, Greiner A (2011) Electrospun nanofiber mats coating-new route to flame retardancy. Polym Adv Technol 22(7): 12051210.

15. Yu X, Wu X, Si Y, Wang X, Yu J, et al. (2019) Waterproof and breathable electrospun nanofibrous membranes. Macromol Rapid Commun 40(8): 1-19.

16. Li X (2019) Waterproof-breathable PTFE nano- and microfiber membrane as high efficiency PM2.5 filter. Polymers (Basel) 11(4): 1-14.

17. Tripathi M, Parthasarathy S, Roy PK (2020) Mechanically robust polyurea nanofibers processed through electrospinning technique. Mater Today Commun. 
18. Udayraj, Talukdar P, Das A, Alagirusamy R (2016) Heat and mass transfer through thermal protective clothing - A review. International Journal of Thermal Sciences 106: 32-56.

19. McQuerry M, DenHartog E, Barker R (2017) Evaluating turnout composite layering strategies for reducing thermal burden in structural firefighter protective clothing systems. Text Res J 87(10): 1217-1225.

20. McQuerry M, Barker R, DenHartog E (2018) Functional design and evaluation of structural firefighter turnout suits for improved thermal comfort: thermal manikin and physiological modelling. Cloth Text Res
J 36(3): 165-179.

21. McQuerry M (2018) Effect of structural turnout suit fit on female versus male firefighter range of motion. Appl Ergon 82: 102974.

22. Silva-Santos MC, PeixotoJJ, Fangueiro R, Gasi F, Baruque-Ramos J (2019) The influence of textile materials on flame resistance ratings of professional uniforms. SN Appl Sci 1(12): 1650.

23. Islam GMN, Ali A, Collie S (2020) Textile sensors for wearable applications: a comprehensive review. Cellulose 27(11): 6103-6131.

For possible submissions Click below: 